\title{
ANNOUNCEMENT
}

\section{THE PAUL GUGGENHEIM PRIZE 1997}

The Board of the Paul Guggenheim Foundation has decided to award the ninth Paul Guggenheim Prize of 12,000 Swiss francs in 1997.

The Paul Guggenheim Prize is periodically awarded to a monograph of major importance in the field of public international law (except European law). The monograph must be of the highest quality and be the work of a young author at the beginning of his/her career. Works submitted may be in the form of published books or of manuscripts intended for publication: they may be written in English, French, German, Italian or Spanish. Works which have already received a prize of a similar nature will not be considered.

Applications accompanied by a curriculum vitae, a list of publications and five copies of the work submitted must be received, no later than 31 January 1997, by: The Paul Guggenheim Foundation, The Graduate Institute of International Studies, 132, rue de Lausanne, 1211 Genève 21 (Switzerland). Applicants are required to specify whether the work has already been awarded a prize.

The Rules pertaining to the Prize may be obtained at the same address. 